\title{
Photograph
}

\section{Lanterns in Marrakesh}

Stefan Mann, $\mathrm{MD}^{1}$

\section{Abstract}

\section{Description}

This photo was taken in Marrakesh, Morocco in 2014. I decided to travel there after a few friends inspired me with their descriptions of a beautiful desert-filled country with kind people, mountains and incredibly delicious food. For me, traveling is truly food for the soul. It allows you to break out of the monotony of work-life and potentially step outside of your comfort zone. I absolutely love exploring various cultures and over the course of my life I have traveled to over thirty countries and have back-packed numerous countries solo. There's no better feeling than embarking on an adventure free of rules and schedules, meeting people from all walks of life and cultures and exploring the beauty of our planet. My days of photography really started with making films of my travels. Capturing special moments with the camera produces a memory that will live on forever. I enjoy making films and choosing music for films almost as much as I enjoy practicing medicine! Photography is a challenging art and science. It takes years to master DSLR cameras and editing programs, but nowadays you really don't need any of that to capture a special moment, all you need is your phone! I highly recommend stepping out of your comfort zone and hitting the road. And if the time is right, get the camera out so you and your family can relive all of the special moments that make up your life.

\section{Keywords}

medicine in the arts; Morocco; photography; travel

\section{Conflicts of Interest}

The author declares he has no conflicts of interest.

The author is an employee of North Florida Regional Medical Center, a hospital affiliated with the journal's publisher.

This research was supported (in whole or in part) by HCA Healthcare and/or an HCA Healthcare affiliated entity. The views expressed in this publication represent those of the author(s) and do not necessarily represent the official views of HCA Healthcare or any of its affiliated entities.

\section{Author Affiliation}

1. North Florida Regional Medical Center, Gainesville, FL

\section{HCA is Healthcare $^{\circ}$}

www.hcahealthcarejournal.com

(c) 2021 HCA Physician Services, Inc. d/b/a Emerald Medical Education
Author affiliations are listed at the end of this article.

Correspondence to:

Stefan Mann, MD

North Florida Regional

Medical Center

6500 W Newberry Rd

Gainesville, FL 32605

(stefan.mann@

hcahealthcare.com) 


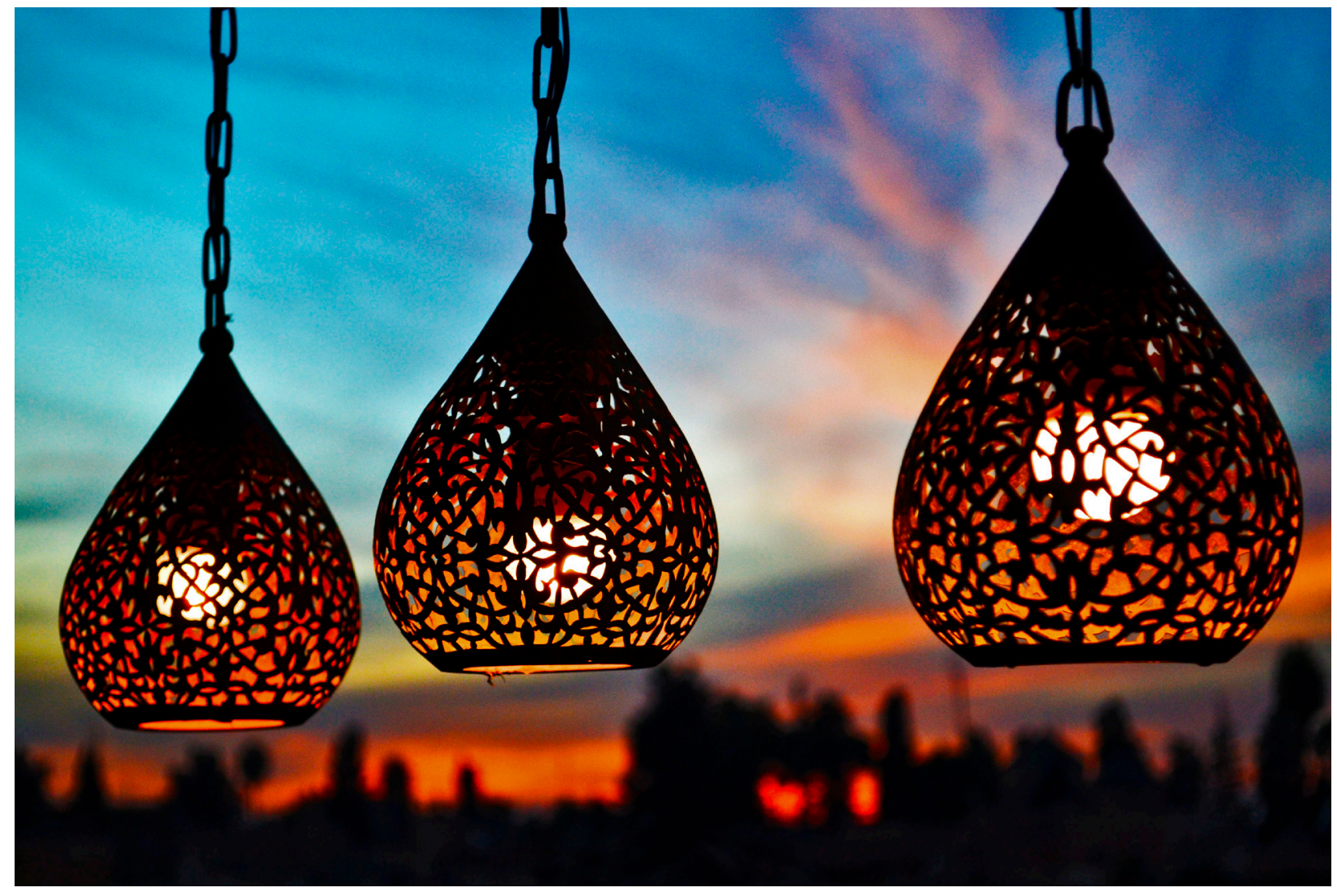

